\title{
Модификация рельефа $n$-поверхности AIGalnN-светодиодов изменением состава газовой смеси при реактивном ионном травлении
}

\author{
(С) Л.К. Марков, И.П. Смирнова, М.В. Кукушкин, А.С. Павлюченко \\ Физико-технический институт им. А.Ф. Иофрфе Российской академии наук, \\ 194021 Санкт-Петербург, Россия \\ E-mail: I.markov@mail.ioffe.ru
}

Поступила в Редакцию 22 января 2020 г.

В окончательной редакции 28 января 2020 г.

Принята к публикации 28 января 2020 г.

Исследовалась зависимость рельефа, возникающего на освободившейся после удаления ростовой подложки поверхности светодиодной гетероструктуры, от состава газовой смеси, применявшейся в процессе реактивного ионного травления светодиодных гетероструктур состава AlGaInN. Показано, что использование смеси, состоящей из $\mathrm{Cl}_{2}$ и $\mathrm{Ar}$ в соотношении 3:2 по скорости потоков приводит к наиболее тонкому рельефу, а газовая смесь $\mathrm{BCl}_{3}$ и $\mathrm{Ar}$ в соотношении 2:1 обеспечивает наибольшие по размеру элементы структуры. Для изучения влияния характера рельефа на квантовый выход светодиодов были изготовлены серии флип-чип светодиодов на кремниевой подложке, которые после удаления ростовой подложки подвергались травлению в разных режимах. Оптимальным для достижения максимального вывода излучения из светодиодного кристалла с длиной волны собственного излучения 460 нм оказалось травление в смеси $\mathrm{Cl}_{2}: \mathrm{BCl}_{3}: \mathrm{Ar}$ в соотношении потоков $6: 10: 11$, приводящее к промежуточным значениям размеров элементов рельефа травления. Изменение характера рельефа в зависимости от состава газовой смеси дает основания предполагать возможность подстройки параметров рельефа под используемую длину волну излучения. Изучение зависимости квантового выхода светодиодных кристаллов от времени травления в рассмотренной трехкомпонентной смеси приводит к оценке оптимального времени травления в районе 30 мин. Результаты настоящей работы могут быть полезны также при поиске условий минимизации отражения кристаллом падающего излучения, например, для фотоприемников.

Ключевые слова: светоизлучающий диод, светоизлучающий кристалл, рельеф поверхности, реактивное ионное травление, флип-чип конструкция, нитрид галлия.

DOI: 10.21883/FTP.2020.06.49386.9353

\section{1. Введение}

Квантовая эффективность широко используемых в настоящее время светодиодов на основе AlGaInN существенным образом ограничена эффектом полного внутреннего отражения (ПВО) света на границах светодиодного кристалла. Поскольку показатель преломления $\mathrm{GaN}$ достаточно высок (близок к 2.5 на длине волны собственного излучения светодиода), то большая часть генерируемого излучения оказывается запертой в кристалле, как в волноводе, затухая на каждом акте прохождения по нему. Введение в конструкцию кристалла рассеивающих свет поверхностей и создание просветляющих покрытий на границах кристалла являются основными приемами борьбы с эффектом ПВО. С этой целью применяются, например, выращивание гетероструктур на предварительно профилированных подложках $[1,2]$, создание прозрачных проводящих контактов, имеющих рельеф на внешней границе [3-5] или градиент показателя преломления в направлении, перпендикулярном плоскости контакта [6,7], формирование фотонных кристаллов $[8,9]$. Одним из эффективных способов создания рассеивающих свет поверхностей является анизотропное травление материала GaN. Поскольку $p$-слой светодиодных гетероструктур имеет малую толщину (как правило, десятые доли мкм) и, следовательно, расположен близко к $p-n$-переходу, а также нестабилен по отношению к различным способам обработки, то для создания рассеивающих свет поверхностей используется $n$-поверхность при условии предварительного удаления ростовой подложки (как правило, сапфировой). Для травления $n$-поверхности $\mathrm{GaN}$ может использоваться электрохимическое травление открывшейся поверхности в растворах $\mathrm{KOH}[10,11]$ или же реактивное ионное травление в хлорсодержащей плазме [12]. Светодиодная структура с удаленной ростовой подложкой может быть использована при создании вертикальных кристаллов, геометрия которых предполагает расположение контактных площадок по обе стороны от гетероструктуры $[11,12]$ или флип-чип кристаллов $[13,14]$, при которой обе контактные площадки вынесены на одну сторону от гетероструктуры, а противоположная сторона используется исключительно для вывода света. Создание рельефа на $n$-поверхности гетероструктуры приводит к существенному увеличению квантовой эффективности светодиодов. Так, в работе [11] наблюдался двух-трехкратный прирост оптической мощности светодиодов после создания рельефа.

Далее мы рассмотрим модификацию параметров рельефа, создаваемого на $n$-поверхности $\mathrm{GaN}$ гетерострук- 
тур, за счет изменения режимов реактивного ионного травления.

\section{2. Результаты эксперимента и их обсуждение}

В настоящей работе использовались светодиодные AlGaInN-гетероструктуры, выращенные на сапфировых подложках методом газофазной эпитаксии из металлоорганических соединений на установке Е300 производства фирмы Veесо. Гетероструктура содержала следующие слои: нелегированный слой $\mathrm{GaN}$ толщиной $\sim 1$ мкм, слой $n$ - $\mathrm{GaN}$ толщиной $\sim 3$ мкм, вспомогательную сверхрешетку из 10 слоев $n$-GaN $/ n-\operatorname{InGaN}$ (3/2.5 мкм), активную область, состоящую из 5 квантовых ям InGaN толщиной 1.6 нм, разделенных барьерами GaN толщиной 2 нм, сверхрешетку из 10 пар слоев $p-\mathrm{AlGaN} / \mathrm{GaN}$ и слой $p$-GaN толщиной 0.1 мкм. Пластины полировались со стороны сапфира для обеспечения качественного удаления сапфировой подложки впоследствии. Затем в гетероструктурах с использованием фотолитографических операций методом реактивного ионного травления (RIE) вытравливались дорожки шириной 0.1 мм на всю глубину гетероструктуры. В результате были сформированы островки с размерами $1.1 \times 1.1$ мм. На структуры наносился контакт к p-области $\mathrm{GaN}$ состава $\mathrm{Ni} / \mathrm{Au}$, который затем усиливался гальваническим золотом толщиной 2 мкм. В дальнейшем структура приваривалась к кремниевой пластине с образованием эвтектического соединения 97.1\% Au:2.9\% Si (указаны \% по массе). После облучения структуры со стороны сапфира импульсом мощного эксимерного KrF-лазера с длиной волны 248 нм гетероструктура освобождалась от ростовой сапфировой подложки и оставалась размещенной на кремниевой пластине $n$-поверхностью вверх. Детали процесса переноса гетероструктур на кремниевые пластины с удалением сапфировой подложки можно найти в статье [15]. Травление гетероструктур с целью получения различного рельефа проводилось реактивным ионным травлением в плазме с разной концентрацией компонентов.

Исследование зависимости параметров рельефа, создаваемого на $n$-поверхности $\mathrm{GaN}$, от состава газовой смеси проводилось на установке реактивного ионного травления RDE 300 производства фирмы Alcatel. Как правило, травление материала нитрида галлия с целью формирования светодиодных кристаллов проводится в газовой смеси, состоящей из трех компонентов: $\mathrm{Cl}_{2}$, $\mathrm{BCl}_{3}$, Ar. Эксперименты проводились при давлении в вакуумной камере 1Па, мощность плазменного разряда составляла $25 \mathrm{BT}$.

В работе исследовались различные соотношения потоков газов.

- Газы подавались в вакуумную камеру таким образом, что соотношение их потоков $\mathrm{Cl}_{2}: \mathrm{BCl}_{3}: \mathrm{Ar}$ составило 6:10:11, т.е. потоки $\mathrm{Cl}_{2}, \mathrm{BCl}_{3}, \mathrm{Ar}$ составили 6,10 и 11 стандартных кубических сантиметров в минуту $(\mathrm{sccm})$ соответственно. Этот режим применяется нами для формирования светодиодных кристаллов при травлении со стороны $p$-поверхности GaN с целью организации доступа к n-области гетероструктуры и разделения кристаллов на пластине. В этом режиме в настоящей работе также были протравлены дорожки в гетероструктуре перед постановкой ее на кремниевую подложку (см. выше).

На рис. 1, $a$ показан результат травления гетероструктуры в выбранном режиме в течение 50 мин в виде изображений, полученных методом растровой электронной микроскопии (РЭМ). Характерной особенностью травления является наличие объектов двух размеров. Более крупные (темные на рисунке) объекты имеют микрометровые размеры в основании и представляют собой нетравленые участки гетероструктуры, поскольку их высота равняется толщине удаленного слоя гетероструктуры. Первоначальное предположение о том, что причиной их возникновения может являться маска из металлического галлия, выделяющегося на поверхности гетероструктуры после процесса удаления ростовой подложки, не нашло подтверждения, поскольку промежуточное снятие галлия погружением гетероструктуры после удаления сапфира в раствор соляной кислоты, не привело к исчезновению более крупных элементов рельефа. На рис. 1, $b$ приведено увеличенное изображение более тонкого рельефа. Как можно видеть из рисунка, он состоит из объектов трубчатой формы с размерами $150-300$ нм. Дальнейшее увеличение времени травления не приводит к внешнему изменению вида рельефа, а увеличивает толщину снимаемого слоя. На рис. 1, представлено изображение поперечного скола образца, травившегося в этом же режиме в течение 100 мин. Стоит отметить, что, как мы рассмотрим далее, избыточное по длительности травление образца, не приводя к увеличению вывода света из гетероструктуры, таит в себе две главные опасности: уменьшение проводимости $n$-слоя $\mathrm{GaN}$ в силу уменьшения его толщины и возможность повреждения $p-n$-перехода при приближении области травления к нему, соответственно приводит к утечкам в изготовленных из гетероструктур светодиодах.

- В следующем эксперименте газовая смесь была двухкомпонентной и не содержала $\mathrm{BCl}_{3}$. Соотношение потоков хлора и аргона $\mathrm{Cl}_{2}: \mathrm{Ar}$ составило $3: 2$ (скорость натекания газов была 15 и $10 \mathrm{sccm}$ соответственно). Поверхность гетероструктуры, полученная в результате травления в течение 50 мин, приведена на рис. $1, d$. Как видно из рисунка, применение данной смеси достаточно эффективно с точки зрения создания развитого рельефа, однако характерные размеры его элементов более тонкие по сравнению с наблюдаемыми в предыдущем эксперименте и составляют величину $\sim(100-150)$ нм.

- Из смеси был исключен $\mathrm{Cl}_{2}$, а соотношение потоков оставшихся газов $\mathrm{BCl}_{3}: \mathrm{Ar}$ составило 2:1 (потоки газов составили 22 и $11 \mathrm{sccm}$ соответственно). Образец травили в течение 50 мин. Характерный рельеф, возникающий при травления в газовой смеси указанного состава, приведен на рис. 1, e. Как видно из рисунка, скорость травле- 


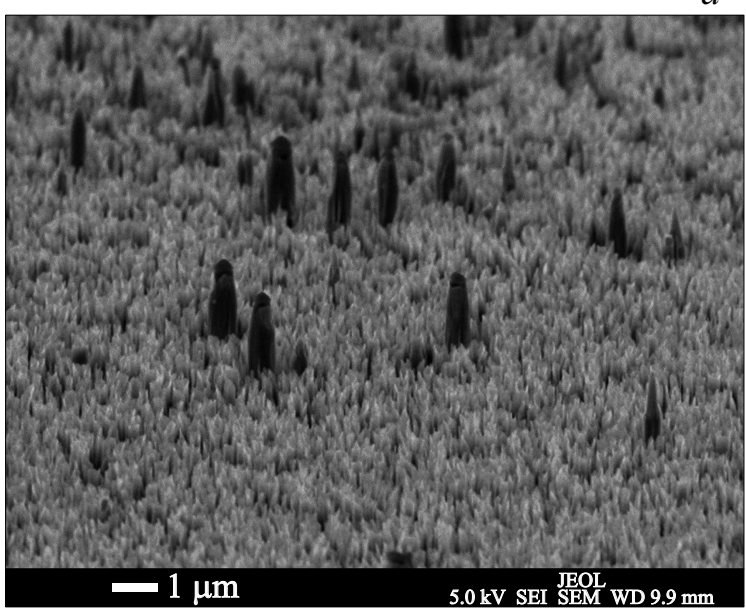

$c$
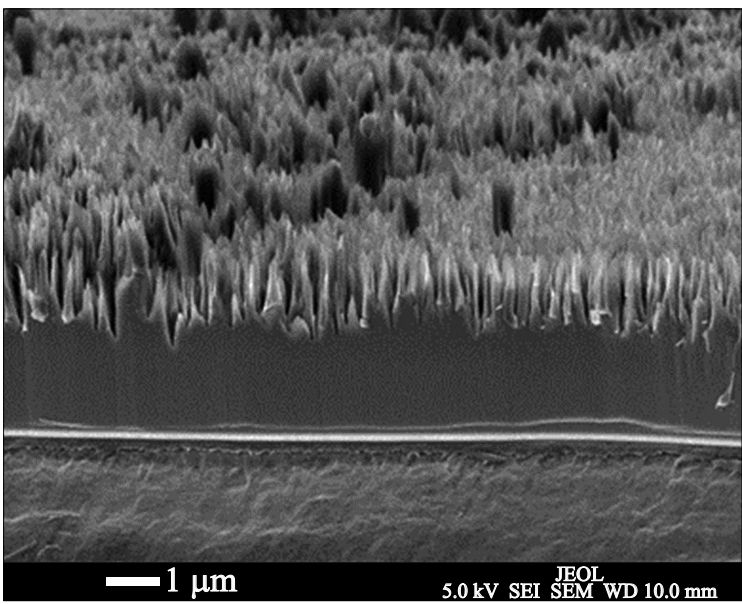

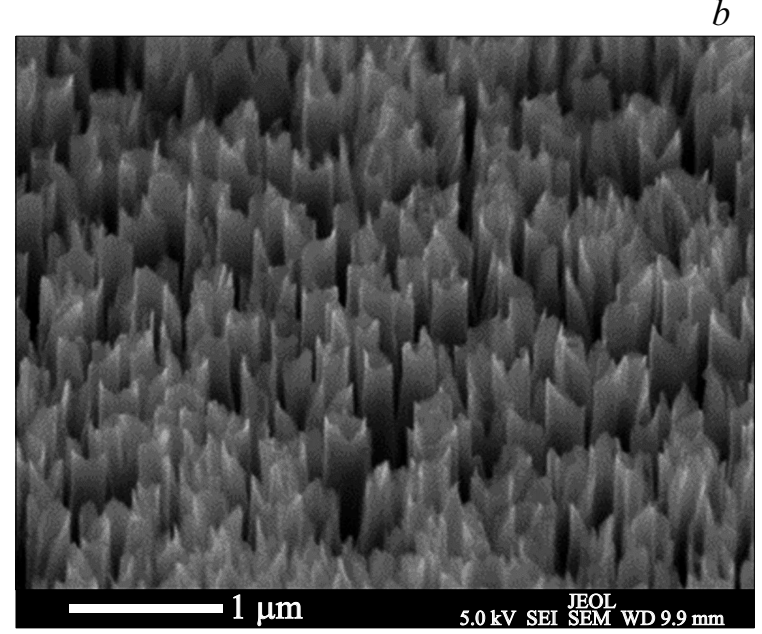

$d$

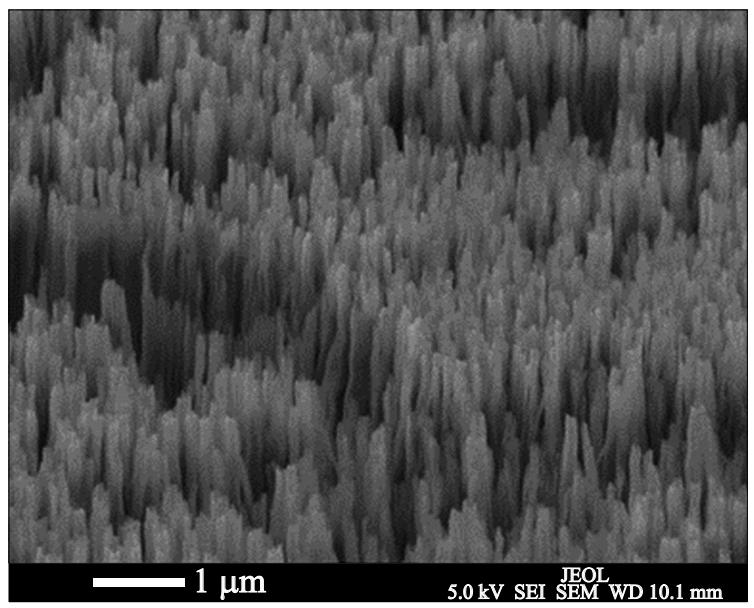

$e$

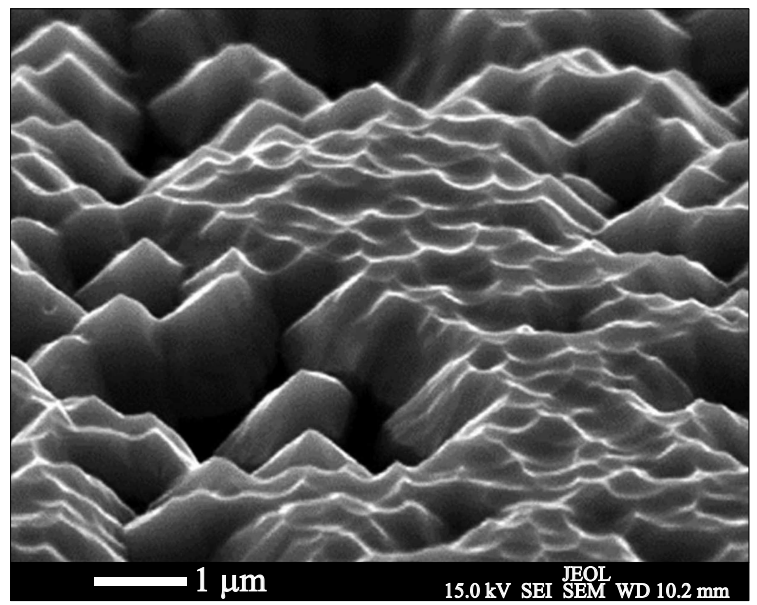

Рис. 1. РЭМ-изображения рельефа, полученного на поверхности гетероструктур в результате травления: в смеси газов $\mathrm{Cl}_{2}, \mathrm{BCl}_{3}$, $\mathrm{Ar}$ в течение 50 мин $(a, b)$; в смеси газов $\mathrm{Cl}_{2}, \mathrm{BCl}_{3}, \mathrm{Ar}$ в течение 100 мин, изображение поперечного скола $(c) ;$ в смеси газов $\mathrm{Cl}_{2}$ и $\mathrm{Ar}$ в течение 50 мин $(d)$; в смеси газов $\mathrm{BCl}_{3}$ и $\mathrm{Ar}$ в течение 50 мин $(e)$. Все изображения получены под наклоном $10^{\circ}$.

ния в отсутствие хлора существенно снизилась, а сам характер рельефа напоминает получаемый обычно травлением по выделенным плоскостям в растворах $\mathrm{KOH}$ [11].

Таким образом, характер рельефа, возникающего на свободной от ростовой подложки поверхности гетеро- структур, зависит от состава используемой при травления газовой смеси. Так, повышение содержания хлора приводит к возникновению более тонкого рельефа, в то время как повышение содержания $\mathrm{BCl}_{3}$ увеличивает размер элементов рельефа. Стоит отметить, что 
полученные нами результаты несколько отличаются от данных работы [12], где исследовалось влияние состава газовой смеси, состоящей из тех же компонент, на рельеф, возникающий при травлении свободной поверхности гетероструктур в индуктивно связанной плазме. По данным работы отсутствие хлора в камере приводило к плоскому, безрельефному травлению гетероструктур, а использование смеси $10 \% \mathrm{BCl}_{3}$ и $90 \% \mathrm{Cl}_{2}$ инициировало появление шарообразных элементов с диаметром $0.5-1$ мКм.

Для оценки влияния получаемого различными методами рельефа были изготовлены флип-чип светодиодные кристаллы с размерами $1.3 \times 1.3$ мм, которые размещались на кремниевой подкристальной плате. Поскольку в светодиодных кристаллах флип-чип конструкции контакты находятся с одной стороны гетероструктуры, а свет выводится через сапфировую подложку, процедура удаления ростовой подложки для них становится возможной после постановки кристалла на плату-носитель. Детали процесса изготовления флип-чип светодиодов с удаленной подложкой детально описаны в работе [16], а детали конструкции дизайна светодиодных кристаллов рассмотрены в работе [15]. Была изготовлена партия светодиодов, которые группами травили в атмосфере трех описанных выше газовых смесей. Длина волны собственного излучения светодиодов составила 460 нм. Для оценки изменения квантового выхода светодиодов их световыводящая поверхность, без формирования линзы, размещалась на фотоприемнике. Измерения проводились при токе накачки светодиодов 400 мА. Полученные данные усреднялись по группам и сравнивались с данными по квантовому выходу этих же кристаллов до процедуры травления, но после удаления ростовой подложки, поскольку присутствие относительно толстой (толщиной в сотни мкм) подложки по сравнению с гетероструктурой (единицы мкм) может изменить условия вывода света и диаграмму направленности светодиода, что исказит достоверность оценки. На рис. 2 приводятся данные по относительному изменению квантового выхода светодиодов, полученному в результате травления в газовых смесях разного состава. Видно, что травление в трехкомпонентной смеси намного эффективнее травления в обеих двухкомпонентных. В то же время, поскольку, как мы обсуждали выше, по данным растровой электронной микроскопии характерные размеры рельефа, создаваемого при травлении в смеси $\mathrm{Cl}_{2}$ : Ar, меньше, чем в рассматриваемой трехкомпонентной смеси, вероятно, данный рельеф может быть предпочтителен при уменьшении длины волны излучения в область ультрафиолетового излучения. С другой стороны, поскольку рельеф травления в смеси без хлора $\left(\mathrm{BCl}_{3}: \mathrm{Ar}\right)$ значительно крупнее, логично предположить, что, варьируя содержание хлора и трихлорида бора, можно настраивать параметры рельефа под длину волны излучения.

Зависимость квантового выхода светодиодов от времени травления изучалась на серии образцов, изготовленных по вышеописанной технологии. Травление проводилось в смеси $\mathrm{Cl}_{2}: \mathrm{BCl}_{3}: \mathrm{Ar}(6: 10: 11)$, использование

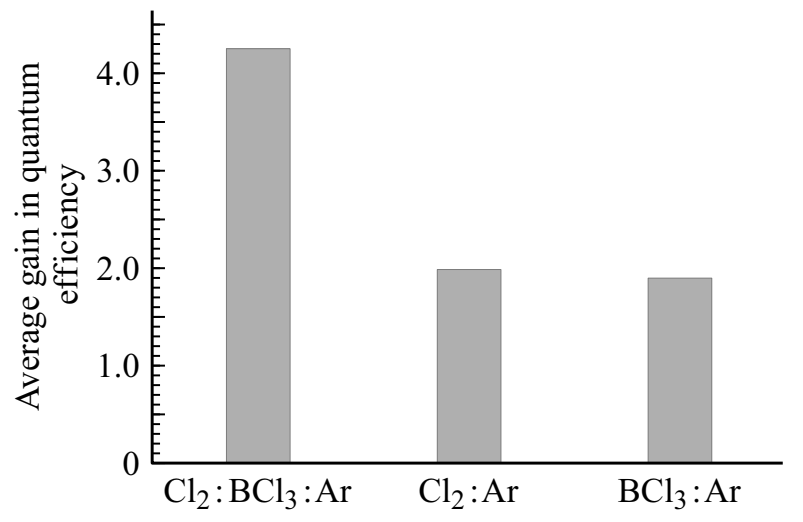

Рис. 2. Зависимость усредненного коэффициента увеличения квантового выхода светодиодов от состава газовой смеси, в которой проводилось травление образцов.

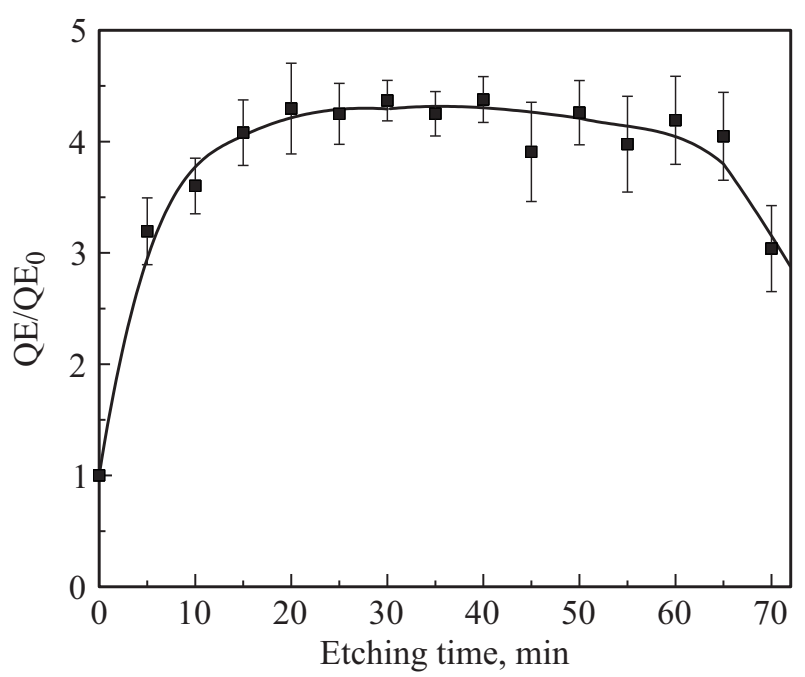

Рис. 3. Зависимость усредненного коэффициента увеличения квантового выхода светодиодов от времени травления в газовой смеси.

которой приводило к наибольшему увеличению квантового выхода светодиодов (рис. 2). Образцы травили с интервалами по 5 мин, после чего их доставали из камеры, измеряли, и снова подвергали травлению. Часть из них показала катастрофические отказы начиная с травления в течение 35 мин. Зависимость изменения квантового выхода (quantum efficiency, QE) от времени травления для светодиодов, выдержавших травление, приведена на рис. 3. Результаты, так же как и в предыдущем эксперименте, делили на данные по квантовому выходу этих же кристаллов до процедуры травления, но после удаления ростовой подложки $\left(\mathrm{QE}_{0}\right)$ и усредняли по группам. На рис. 3 также показаны стандартные отклонения полученных величин, вычисленные для светодиодов, не имевших катастрофических повреждений. Как видно из рисунка, травления в течение 20 мин в среднем достаточно для достижения максимального квантового выхода светодиода, дополнительные 20 мин травления практически не меняют квантовый выход светодиода, а в дальнейшем 
зарождается тенденция к его уменьшению. По всей вероятности, уменьшение квантового выхода светодиодов в этом диапазоне времен травления, как обсуждалось выше, связано не с изменением характера рельефа, а с уменьшением толщины $n$-слоя $\mathrm{GaN}$ и повреждениями $p-n$-перехода при приближении области травления к нему. Бороться с возможным негативным влиянием глубокого травления можно посредством увеличения толщины нелегированного слоя $\mathrm{GaN}$, однако ход кривой на рис. 3 говорит о прекращении роста эффективности вывода излучения при больших временах. Если исходить из данных рис. 3, оптимальное время травления составляет 30 мин, поскольку увеличение квантового выхода рассматриваемых светодиодов характеризуется минимальным стандартным отклонением в этой точке. Согласно нашему опыту, данное время может считаться оптимальным с точки зрения достижения компромисса между получением максимального квантового выхода светодиода и минимизацией угрозы деградационных процессов в светодиодном кристалле.

Хотелось бы отметить, что дальнейшая модификация рельефа, создаваемого на свободной поверхности гетероструктур после удаления ростовой подложки, возможна за счет комбинированного травления, т.е. сочетания реактивного ионного травления с жидкостным травлением (например, в растворах $\mathrm{KOH}$ или соляной кислоты). В настоящее время нами проведены серии экспериментов в этой области, результаты которых будут опубликованы в ближайшее время.

\section{3. Заключение}

Таким образом, состав газовой смеси оказывает существенное влияние на параметры рельефа при травлении свободной поверхности $\mathrm{GaN}$, образовавшейся после удаления ростовой подложки. Использование смеси $\mathrm{Cl}_{2}: \mathrm{Ar}$ $(3: 2)$ приводит к наиболее тонкому рельефу, в то время как смесь $\mathrm{BCl}_{3}: \mathrm{Ar}(2: 1)$ обеспечивает наибольшие по размеру элементы структуры, напоминающие наблюдаемые обычно при травлении $\mathrm{GaN}$ по выделенным плоскостям в растворах $\mathrm{KOH}$. Оптимальным с точки зрения достижения максимального вывода излучения из светодиодного кристалла с длиной волны собственного излучения $460 \mathrm{Hм}$ стало использование смеси $\mathrm{Cl}_{2}: \mathrm{BCl}_{3}: \mathrm{Ar}$ $(6: 10: 11)$, приводящее к промежуточным размерам элементов рельефа травления. Изучение зависимости квантового выхода светодиодных кристаллов от времени травления образцов приводит к оценке оптимального времени травления $\sim 30$ мин.

Зависимость характера рельефа от состава газовой смеси дает основания предполагать возможность подстройки параметров рельефа под используемую длину волну излучения. Стоит отметить также, что данные, полученные в настоящей работе, могут быть полезны при решении противоположной задачи: поиска рельефа для оптимального поглощения кристаллом падающего излучения, как, например, при разработке приборов фотовольтаики.

\section{Конфликт интересов}

Авторы статьи заявляют об отсутствии конфликта интересов.

\section{Список литературы}

[1] Y.J. Lee, J.M. Hwang, T.C. Hsu, M.H. Hsieh, M.J. Jou, B.J. Lee, T.C. Lu, H.C. Kuo, S.C. Wang. IEEE Photon. Technol. Lett., 18, 1152 (2006).

[2] S.-M. Jeong, S. Kissinger, D.-W. Kim, S. Jae Lee, J.-S. Kim, H.-K. Ahn, C.-R. Lee. J. Cryst. Growth, 312, 258 (2010).

[3] J.H. Kang, J.H. Ryu, H.K. Kim, H.Y. Kim, N. Han, Y.J. Park, P. Uthirakumar, C.-H. Hong. Opt. Express, 19, 3637 (2011).

[4] R.H. Horng, C.C. Yang, J.Y. Wu, S.H. Huang, C.E. Lee, D.S. Wuu. Appl. Phys. Lett., 86, 221101 (2005).

[5] H. Huang, J. Hu, H. Wang. J. Semicond., 35, 084006 (2014).

[6] M.J. Park, C.U. Kim, S.B. Kang, S.H. Won, J.S. Kwak, C.-M. Kim, K.J. Choi. Adv. Opt. Mater., 5, 1600684 (2017).

[7] Л.К. Марков, А.С. Павлюченко, И.П. Смирнова. ФТП, 53, 181 (2019).

[8] D. Ge, X. Huang, J. Wei, P. Qian, L. Zhang, J. Ding, S. Zhu. Mater. Res. Express, 6, (2019).

[9] H.H. Yen, H.C. Kuo, W.Y. Yeh. Phys. Status Solidi C, 5, 2152 (2008).

[10] Y.J. Sung, M.-S. Kim, H. Kim, S. Choi, Y.H. Kim, M.-H. Jung, R.-J. Choi, Y.-T. Moon, J.-T. Oh, H.-H. Jeong. Opt. Express, 27, 29930 (2019).

[11] T. Fujii, Y. Gao, R. Sharma, E.L. Hu, S.P. DenBaars, S. Nakamura. Appl. Phys. Lett., 84, 855 (2004).

[12] D.W. Kim, H.Y. Lee, M.C. Yoo, G.Y. Yeom. Appl. Phys. Lett., 86, 052108 (2005).

[13] J.J. Wierer, D.A. Steigerwald, M.R. Krames, J.J. O'Shea, M.J. Ludowise, G. Christenson, Y.-C. Shen, C. Lowery, P.S. Martin, S. Subramanya, W. Götz, N.F. Gardner, R.S. Kern, S.A. Stockman. Appl. Phys. Lett., 78, 3379 (2001).

[14] S. Zhou, X. Liu, H. Yan, Z. Chen, Y. Liu, S. Liu. Opt. Express, 27, A669 (2019).

[15] Л.К. Марков, И.П. Смирнова, А.С. Павлюченко, М.В. Кукушкин, Е.Д. Васильева, А.Е. Черняков, А.С. Усиков. ФТП, 47, 386 (2013).

[16] И.П. Смирнова, Л.К. Марков, Д.А. Закгейм, Е.М. Аракчеева, М.Р. Рымалис. ФТП, 40, 1397 (2006).

Редактор Л.В. Шаронова 


\section{Modification of $n$-surface relief \\ by changing the gas mixture composition during reactive ion etching of AIGalnN LEDs}

L.K. Markov, I.P. Smirnova, M.V. Kukushkin, A.S. Pavluchenko

loffe Institute,

194021 St. Petersburg, Russia

Abstract In this work, the kind of relief produced during reactive ion etching an AlGaInN LED heterostructure on the surface, which became free after removal of the growth substrate, has been studied as a function of the gas mixture composition used in the etching process. It has been shown that the use of the mixture consisting of $\mathrm{Cl}_{2}$ and $\mathrm{Ar}$ in the ratio of $3: 2$ in terms of flow rates, respectively, leads to the thinnest relief, while the gas mixture of $\mathrm{BCl}_{3}$ and $\mathrm{Ar}$ in the ratio of $2: 1$ provides the largest structural elements. To study the effect of the kind of a relief on the LED quantum efficiency, flip-chip LEDs on the silicon substrate were fabricated, which were etched in different modes after removal of the growth substrate. Etching in the $\mathrm{Cl}_{2}: \mathrm{BCl}_{3}: \mathrm{Ar}$ mixture with the flow ratio of $6: 10: 11$, which leads to the intermediate sizes of etching relief elements, was optimal to obtain the maximum light extraction from a LED chip at the wavelength of $460 \mathrm{~nm}$. The dependence of kind of relief as a function of the gas mixture composition suggests that the parameters of the relief can be adjusted to the wavelength used. The study of the dependence of quantum efficiency of LED chips on the etching time in the considered three-component mixture leads to the estimation of the optimum etching time to be $\sim 30 \mathrm{~min}$. The of this work can also be useful when searching for conditions to minimize the reflection of incident light by the chip, e.g. for photodetectors. 